\title{
Costly Collateral and the Public Supply of Liquidity
}

Philip Schellekens 


\title{
IMF Working Paper
}

Research Department

\section{Costly Collateral and the Public Supply of Liquidity}

\author{
Prepared by Philip Schellekens ${ }^{\mathfrak{1}}$ \\ Authorized for distribution by Donald J. Mathieson
}

July 2000

\begin{abstract}
The views expressed in this Working Paper are those of the author(s) and do not necessarily represent those of the IMF or IMF policy. Working Papers describe research in progress by the author(s) and are published to elicit comments and to further debate.
\end{abstract}

This paper addresses two complications arising from the use of collateral rcquirements in debt contracts between wealth-constrained entrepreneurs and banks. First, costly asset liquidation is found to enhance the susceptibility of dcbt finance to interest rate volatility. Second, aggregate uncertainty in conjunction with limitcd bank capitalization is shown to produce excessive credit constraints that, under certain conditions, justify the public supply of liquidity. The paper suggests applications with respect to modcls of interest rate smoothing and self-fulfilling currency crises.

\section{JEL Classification Numbers: E44, E5}

Keywords: Debt Finance, Collateral, Credit Constraints, Asset Price Volatility

Author's E-Mail Address: schellek@mit.edu

\footnotetext{
${ }^{1}$ Massachusetts Institute of Technology and UFSIA. For helpful comments and discussions, I am indebted to Klaas Baks, Monica Baumgarten de Bolle, Torbjorn Becker, Nada Choueiri, Xavier Debrun, Rupa Dutta-Gupta, Robert Flood, Charles Goodhart, Florence Jaumotte, Nobu Kiyotaki, Subir Lall, Eric Le Borgne, Paul Masson, Don Mathieson, Brieuc Monfort, Jef Plasmans, Ken Rogoff, Jorge Roldos and Amadou Sy. I gratefully acknowledge the Emerging Markets Studies Division at the IMF Research Department, where this project was started. I also thank the Fund for Scientific Research (Flanders, Belgium) for financial support. Correspondencc: Department of Economics, MIT, 50 Memorial Drive, Cambridge, MA 02142-1347, USA. Fax: +1617-253-1330
} 
I. Introduction 3

II. A Model of Costly Asset Collateralization 5

A. The Basic Setup 5

B. Welfare Implications of Non-Verifiability and Costly Asset Liquidation 9

C. Underinvestment and Credit Constraints 10

D. Susceptibility to Interest Rate Shocks 12

$\begin{array}{ll}\text { III. Aggregate Uncertainty } & 13\end{array}$

A. Contracting Under Aggregate Uncertainty 13

B. Contingent Contract 15

C. Uncontingent Contract 16

IV. Credit Constraints, Bank Solvency and the Public Supply of Liquidity 17

$\begin{array}{ll}\text { A. Credit Constraints Under Aggregate Uncertainty } & 17\end{array}$

B. Bank Solvency Under Aggregate Uncertainty 18

C. The Public Supply of Liquidity 20

$\begin{array}{ll}\text { V. Concluding Remarks } & 21\end{array}$

$\begin{array}{ll}\text { References } & 23\end{array}$ 


\section{INTRODUCTION}

Credit market imperfections, resulting from informational asymmetries between borrowers and lenders, create moral hazard and adverse selection problems that make lenders reluctant to lend and leave borrowers deprived from credit. Credit constraints disrupt the essential function of the financial system: to channel funds to those with the most productive investment opportunities. If this role is not performed well, the economy does not operate efficiently and economic growth will be hampered. One important way for society to deal with such problems has been to require collateral or net worth as a condition to the provision of finance.

The central issue explored in this paper is that the positive role of collateral in alleviating informational asymmetry needs to be balanced with two potential complications: (i) the problem that the seizure of collateral may be associated with a possibly large cost of liquidation and (ii) the problem that the use of collateral increases the vulnerability of external finance to asset price volatility.

The model that is presented here develops an incomplete contracting framework where wealth-constrained entrepreneurs cannot commit project returns since these are assumed to be non-verifiable to courts. The informational asymmetry creates an extreme form of moral hazard that makes the use of collateral a necessary condition for the provision of finance. However, because of costly asset liquidation, optimal collateralization is generally incomplete. The model illustrates the interaction between leverage and collateralization and shows under which conditions underinvestment and credit constraints occur. In addition, we show that collateralized finance may be highly susceptible to interest rate shocks.

The model further addresses the impact of aggregate asset price uncertainty on the borrower-lender relationship. Particularly when borrowers are poorly capitalized, aggregate uncertainty affects the nature of the optimal contract (leading to a stronger degree of asset price contingency). Highlighting the case where also banks are poorly capitalized, it is shown how aggregate uncertainty amplifies the extent to which wealth-constrained entrepreneurs are deprived from credit. We find that there is a role for the public supply of liquidity when banks face tight solvency constraints and collateral is subject to much asset price volatility. The type of state-contingent government intervention that arises from this model may also be interpreted as countercyclical monetary policy.

The paper concludes with a brief discussion of a number of policy-related applications of the model. We argue that the framework may be used to study the desirability of interest rate smoothing and to provide micro-foundations for second-generation currency crisis models.

How does this paper relate to the literature? There is a large body of research that has focused on the microeconomic role of collateral in alleviating moral hazard and adverse 
selection problems. A common theme of this literature is that collateral requirements lower the hurdle to external finance by limiting the loss of the lender in the case of default. In the presence of adverse selection, collateral may be used by lenders to sort borrowers according to their risk profile. Borrowers with a high default probability reveal themselves by rejecting contracts with low loan rates and high collateral requirements. As a result, high risks pay a higher loan rate and are not required to put down any collateral. Low risks put down collateral but pay a lower loan rate (see, for example, Bester, 1985).

If moral hazard is the concern, collateral may serve as an incentive device that motivates borrowers to behave diligently. In this context, Boot, Thakor and Udell (1991) study the relation between collateral and borrower risk in the presence of a repossession cost but take the availability of collateral as exogenous. Our paper corresponds most closely to this branch of thinking. We assume an extreme form of moral hazard, enabling the borrower to divert all of the project returns in the case of success. A major difference however is that we deviate from the constant project size assumption that is common in this literature. This enables us to study the consequences of moral hazard and liquidation costs for the optimal or, if credit-constrained, feasible scale of operation. Hart and Moore (1994) develop a theory of debt that is also based on an extreme moral hazard problem. They assume that the entrepreneur-borrower has special skills (so that he cannot be costlessly replaced) and that he can credibly threaten to repudiate the contract by withdrawing his human capital. As a result, project returns will be perfectly divertable. In contrast, our model derives the divertability of returns from the assumption that returns are not verifiable to courts. A further difference is that the Hart-Moore set-up is entirely deterministic, whereas our model addresses the consequences of uncertainty about the value of collateral for the ex ante design of the optimal contract.

Recently, a growing body of research has emerged on the macroeconomics of collateral. This new literature has studied how collateral (and net worth) requirements, as a result of microeconomic credit market imperfections, may make the macroeconomy more vulnerable to unanticipated shocks. One branch of research has focused on aggregation problems, showing how the financial sector may lose its ability to aggregate, and efficiently reallocate, resources in response to a shock. Holmstrom and Tirole $(1997,1998)$ show how shocks may lead to credit rationing when financial intermediaries face a moral hazard problem or when the aggregate collateral of private agents does not satisfy their liquidity needs. Caballero and Krishnamurthy (1999) introduce a distinction between domestic and international collateral and show how the aggregate insufficiency of international collateral may cause financial turmoil.

A second branch of research has focused on level problems associated with shocks. The level of borrowing, or the degree of leverage, may become highly susceptible to shocks that either directly or indirectly affect the value of collateral or net worth. This branch of research has shown that small shocks may lead to persistent and amplified business cycle fluctuations. In a seminal article, Bernanke and Gertler (1989) develop a framework where 
endogenous procyclical movements in net worth magnify investment and output fluctuations. An income-accelerator effect on investment emerges as higher income relaxes borrowing constraints. Kiyotaki and Moore $(1997,1999)$ construct a dynamic general equilibrium model with flow and stock effects on credit-constrained entrepreneurs. Not only does higher profit alleviate credit constraints in the future, but the resulting asset price response also magnifies the degree to which credit constraints bind today. Our model fits into this line of research. We also focus on level problems linked to collateralized external finance. A major difference, however, is that we highlight the role of bank balance sheets in constraining the ability of entrepreneurs to find project finance. Unlike previous work, we link the nature of the optimal contract to the interaction between the balance sheets of banks and the degree of asset price uncertainty. It is this interaction that leads to a further tightening of credit constraints, creating scope for welfare-enhancing policy intervention.

\section{A Model of Costly Asset Collateralization}

The purpose of this section is to set up a framework where collateral requirements emerge as an element of an optimal loan contract between wealth-constrained entrepreneurs and banks. The model features both benefits and costs associated with the use of collateral. On the positive side, collateral requirements may reduce problems of asymmetric information. In this model, collateral serves as incentive device that eliminates the desire of borrowers to strategically default. On the negative side, collateral requirements may also create a number of independent problems. One complication that we explore in this section concerns the fact that liquidation of collateralized assets is typically costly.

The model identifies productive assets as the source of collateral. Assets serve both as security against loan default and as inputs in the process of production. The borrower in this model will want to be leveraged to reach the optimal scale of operation. Leverage and asset collateralization are mutually reinforcing. Higher leverage expands the borrower's asset base that can be collateralized. Higher collateralization contributes to loan security and thereby creates the very possibility of leveraging.

We first discuss the basic model. We then revisit the welfare implications of the crucial assumptions of the model. To conclude this section, we examine a number of implications of the model: underinvestment, credit constraints and the susceptibility of the optimal contract to interest rate shocks.

\section{A. The Basic Setup}

Consider an economy that is populated with a continuum of identical risk neutral banks and entrepreneur-borrowers. The representative bank competes for loans and deposits in a perfectly competitive market. Bank loans are assumed to be the entrepreneur's only source of external finance. Banks have access to an abundant supply of funds at the riskless 
net rate $r$. As a result, (i) the net return to depositors equals $r$, (ii) the expected profit of the entrepreneur-borrower is maximized subject to break-even and informational constraints, and (iii) the expected profit of the bank equals zero.

The entrepreneur has access to a risky productive technology. An entrepreneur with asset base of size $k$ can start a project at date 0 that returns $\widetilde{R} k$ at date 1 with $\widetilde{R}=R$ in the case of success and $\widetilde{R}=0$ in the case of failure. Throughout the paper we assume that $R$ is large. The probability of success is given by $p$. Assets in this economy could refer to durables such as land, project returns to nondurables such as fruit. We take nondurables as the numeraire in this economy and denote the relative price at times 0 and 1 by $q_{0}$ and $q_{3}$ respectively. Operation of the project is subject to a utility cost given by $c k^{2} / 2$ (with $c>0$ ). The utility cost is also expressed in terms of the numeraire.

The entrepreneur is wealth-constrained. He is endowed with an asset base of size $w$ which does not enable the maximum possible extraction of surplus from his productive technology. The entrepreneur therefore wants to leverage the scale of production by borrowing from the bank. If the optimal project size is $k$, the entrepreneur needs to finance a purchase of $k-w$ assets by borrowing a sum of $b \equiv q_{0}(k-w)$. The fraction of the asset base that is externally financed is denoted by $f \equiv(k-w) / k$ with $0 \leq f \leq 1$. Autarky corresponds to $f=0$ with $b=0$ and $k=w$. Full external finance corresponds to $f=1$ with $b \equiv q_{0} k$ and $w=0$.

Two critical assumptions affect the nature of resource transfers in this economy between banks and entrepreneurs.

\section{A1 (Incomplete Contracts). Returns $\widetilde{R}$ are not verifiable to courts.}

This assumption motivates why contracts cannot be written contingent on the realization of the productivity shock. Since the realization of $\widetilde{R}$ is not verifiable to courts, returns cannot be pledged in the case of success. This assumption creates a role for an incentive device such as the security of collateral.

A2 (Cost of Specificity). Asset liquidation is costly.

A cost of specificity arises in the valuation of the asset. It is assumed that the inside value of the asset exceeds its outside value. This wedge is measured by $1-\beta$ with $0<\beta<1$ and is referred to as the liquidation cost. Such a cost may arise, for example, due to limited asset redeployability (Shleifer and Vishny, 1992) or due to inefficiencies associated with the transfer of ownership (e.g. as a result of bankruptcy costs). This assumption identifies a cost for the provision of incentives. 
The optimal contractual arrangement between bank and entrepreneur will specify (i) the degree of leverage, (ii) the net loan rate and (iii) the degree of asset collateralization. The degree of leverage determines asset base $k$ given an endowment of $w$. The net loan rate is denoted by $\alpha$ and determines what the entrepreneur is expected to voluntarily repay out of the project returns. The degree of asset collateralization is denoted by $\gamma$ (with $0 \leq \gamma \leq 1$ ) and determines the fraction of the asset base which the bank is entitled to seize if the entrepreneur defaults. At time 0 , the entrepreneur receives a sum of $b \equiv q_{0}(k-w)$. At time 1 , the entrepreneur repays $(1+\alpha) b$; otherwise, the bank liquidates $\gamma$ of the asset base yielding $\beta \gamma q_{1} k$ in proceeds.

The problem to solve is then given by:

$$
\max _{k, \alpha, \gamma} p\left(R+q_{1}\right) k-p(1+\alpha) q_{0}(k-w)+(1-p)(1-\gamma) q_{1} k-(1+r) q_{0} w-\frac{c}{2} k^{2}
$$

subject to

$$
\begin{gathered}
(1+\alpha) q_{0}(k-w) \leq \beta \gamma q_{1} k \\
p(1+\alpha) q_{0}(k-w)+(1-p) \beta \gamma q_{1} k \geq(1+r) q_{0}(k-w)
\end{gathered}
$$

and

$$
\begin{aligned}
& p\left(R+q_{1}\right) k-p(1+\alpha) q_{0}(k-w)+(1-p)(1-\gamma) q_{1} k-(1+r) q_{0} w-\frac{\mathcal{c}}{2} k^{2} \\
& \geq p\left(R+q_{1}\right) w-(1+r) q_{0} w-\frac{c}{2} w^{2} \geq 0
\end{aligned}
$$

where the constraints are respectively the incentive compatibility (IC) constraint of the entrepreneur and the individual rationality (IR) constraints of the bank and the entrepreneur. Implicit in the optimization problem is the assumption that the loan rate repayment does not exceed $R$ and we assume that this is always the case. For now, we restrict attention to the case where the collateral constraint is not binding $(\gamma<1)$. We will revisit this restriction at the end of this section.

The maximand expresses the expected utility of the entrepreneur obtained under a contract with parameters $(k, \alpha, \gamma)$. It consists of the following components. In the case of success, the entrepreneur earns the return, keeps the asset and repays the loan. In the case of failure, the entrepreneur earns no return and keeps the part of the asset base that is not collateralized. In each case, the entrepreneur foregoes the opportunity to earn the riskless rate on his endowment and incurs operational costs $c k^{2} / 2$. Because of the non-verifiability of 
returns, the entrepreneur could always strategically default and claim failure in the case of success. The IC constraint rules out this possibility. The value of the outstanding debt can never exceed the value of liquidated collateral to the bank, otherwise the entrepreneur would be able to renegotiate a lower loan rate. The IR constraint of the bank requires that the expected revenue from loan-making covers the cost of deposit-taking. The sources of income are loan repayment $(1+\alpha) q_{0}(k-w)$ and liquidation proceeds $\beta \gamma q_{1} k$. The IR constraint of the entrepreneur requires that signing the contract is at least as profitable as remaining in autarky. Of course, for the entrepreneur to invest in autarky, production must be more profitable than depositing the endowment.

Since the supply of funds is perfectly elastic at $r$, competition among banks drives the expected return from a loan down to the cost of borrowing. The bank's IR constraint therefore binds and, after rearranging, we obtain:

$$
\begin{aligned}
1+\alpha & =\frac{1+r}{p}-\beta \frac{1-p}{p} \frac{q_{1}}{q_{0}} \gamma \frac{k}{k-w} \\
& =\frac{1+r}{p}-\beta \frac{1-p}{p} \frac{q_{1}}{q_{0}} \frac{\gamma}{f},
\end{aligned}
$$

where $q_{1} / q_{0}$ is the gross capital gain and $\gamma / f$ is the degree of relative collateralization. The latter ratio measures the extent to which collateralization exceeds the fraction of external finance and is an important determinant of the cost of external finance. Substitution of (2) into the maximand yields the following problem:

$$
\max _{k, \gamma}\left(p R+q_{1}\right) k-(1+r) q_{0} k-(1-p)(1-\beta) \gamma q_{1} k-\frac{c}{2} k^{2}
$$

subject to the IC and IR constraints of the entrepreneur. From this formulation it is clear that the use of collateral as an incentive device $(\gamma>0)$ is costly. Therefore, no more collateral will be used than is necessary to provide incentives. Thus, the IC constraint binds and the optimal degree of collateralization is pinned down at:

$$
\gamma=\frac{1+\alpha}{\beta} \frac{q_{0}}{q_{1}} \frac{(k-w)}{k}
$$

Substituting this into (2) gives $\alpha=r$. As a result, we have:

$$
\gamma=\frac{1+r}{\beta} \frac{q_{0}}{q_{1}} \frac{(k-w)}{k}
$$

or 


$$
\frac{\gamma}{f}=\frac{1+r}{\beta} \frac{q_{0}}{q_{1}}
$$

This latter expression has a nice interpretation: interest rate increases, asset price depreciation and costly liquidation all lead to a larger fraction of the entrepreneur's equity stake being at risk.

Substituting (4) into (3) leads to the following problem:

$$
\max _{k}\left(p R+q_{1}\right) k-(1+r) q_{0} k-\frac{(1-p)(1-\beta)(1+r)}{\beta} q_{0}(k-w)-\frac{c}{2} k^{2}
$$

subject to the entrepreneur's IR constraint. We will from now assume that external finance is not too costly so that the entrepreneur's IR constraint will not be violated. The optimal contract can then be characterized by:

$$
\begin{aligned}
k^{*} & =\frac{p R+q_{1}-(1+r) q_{0}}{c}-\frac{(1-p)(1-\beta)(1+r) q_{0}}{\beta c} \\
\alpha^{*} & =r \\
\gamma^{*} & =\frac{(1+r)}{\beta} \frac{q_{0}}{q_{1}} \frac{\left(k^{*}-w\right)}{k^{*}} .
\end{aligned}
$$

Substituting $k^{*}, \alpha^{*}$ and $\gamma^{*}$ into the entrepreneur's objective function (1) yields:

$$
W^{*}=\frac{1}{2 c}\left(p R+q_{1}-(1+r) q_{0}-\frac{(1-p)(1-\beta)(1+r) q_{0}}{\beta}\right)^{2}+\frac{(1-p)(1-\beta)(1+r)}{\beta} q_{0} w
$$

\section{B. Welfare Implications of Non-Verifiability and Costly Asset Liquidation}

Non-verifiability of returns and costly asset liquidation are the crucial features of the environment we studied. To examine their welfare implications, we now look at what the contract would be if assumptions A1 and A2 did not hold.

If returns are verifiable, it is obvious from (3) that the optimal contract does not involve asset collateralization. The distortionary cost of collateral liquidation could be avoided by relying entirely on loan rate repayment. Consequently, the scale of production is at its first-best level. From (2) it then follows that the loan rate includes a default premium. The optimal contract can thus be summarized by: 


$$
\begin{aligned}
k & =\frac{p R+q_{1}-(1+r) q_{0}}{c} \\
\alpha & =\frac{1+r}{p}-1 \\
\gamma & =0 .
\end{aligned}
$$

Welfare is at its first-best level and is given by:

$$
W=\frac{1}{2 c}\left(p R+q_{1}-(1+r) q_{0}\right)^{2} .
$$

If asset liquidation is not costly, loan rate repayment and collateral liquidation are perfect substitutes. Changes in the degree of collateralization no longer lead to changes in welfare. The optimal contract in this environment is then characterized by:

$$
\begin{aligned}
k & =\frac{p R+q_{1}-(1+r) q_{0}}{c} \\
\alpha & =r \\
\gamma & =(1+r) \frac{q_{0}}{q_{1}} \frac{(k-w)}{k} .
\end{aligned}
$$

Welfare again equals its first-best level.

If asset liquidation is not costly and returns are verifiable, the first best again obtains but the loan rate and degree of collateralization would be indeterminate.

\section{Underinvestment and Credit Constraints}

One implication of the model is that non-verifiability, in conjunction with costly asset liquidation, leads to underinvestment compared to the first-best economy:

$$
k^{*}<\frac{p R+q_{1}-(1+r) q_{0}}{c} .
$$

Note that the liquidation cost has a nonlinear effect on production. This is caused by two interacting forces. On the one hand, because of the zero profit condition of the bank, the ultimate burden of the liquidation cost falls on the entrepreneur. The higher the liquidation cost, the more the entrepreneur will loose per unit of collateral in the case of default. On the other hand, a higher liquidation cost necessitates the bank to require more collateral so that 
the proceeds from liquidation remain constant. It is these two reinforcing mechanisms that make the entrepreneur want to decrease external borrowing.

When we interpret the liquidation cost as a metaphor for weak contractual enforcement, the previous finding relates to the observation made by Krishnamurthy (1999) that collateral is likely to be scarcer in less developed economies. Using a simple measure of financial aggregate collateral (the ratio of domestic credit to GDP), he finds values of 0.4 for less developed economies such as India or Turkey and 1.25 for more developed economies such as UK or USA. This can be explained by the following circular problem. On the one hand, weaker enforcement mechanisms lead to an environment where the writing of contracts is more difficult and therefore more collateral is required. On the other hand, the same problem of weak enforcement may lead to a reduced supply of collateralizable assets. If property rights, for example, are not respected, not even land qualifies as collateral.

Another, potentially more harmful, implication is that some agents will be creditconstrained. In the context of this model, non-verifiability is a necessary condition for credit constraints. Given that returns are non-verifiable, a high liquidation cost makes it more likely that some agents with limited endowments will be credit-rationed. To see this, note that the upper bound on the degree of collateralization $\left(\gamma^{\max }\right)$ is unity. This derives from the assumption that only assets can be credibly committed as a security. Recall that the entrepreneur's binding IC constraint and the bank's binding IR constraint imply:

$$
(1+r) q_{0}(k-w)=\beta \gamma q_{1} k
$$

As a consequence, for a given degree of leverage, high interest rates, high liquidation costs or depreciating asset prices must be compensated for by stronger collateral requirements. Otherwise the entrepreneur could not be motivated to repay in the case of success and the bank would not be able to break even. It is possible though that the degree of collateralization hits its upper bound:

$$
\frac{1+r}{\beta} \frac{q_{0}}{q_{1}} \frac{(k-w)}{k}=\gamma^{\max }=1
$$

If this is the case, the bank reduces its exposure in order to break even. The maximum fraction of external finance consistent with the bank breaking even is then given by:

$$
f^{\max }=\frac{\left(k^{\max }-w\right)}{k^{\max }}=\frac{\beta}{1+r} \frac{q_{1}}{q_{0}} .
$$

Whether or not the entrepreneur is credit-constrained is determined by the following lower bound on his endowment: 


$$
\begin{aligned}
w^{\min } & =\left(1-\frac{\beta}{1+r} \frac{q_{1}}{q_{0}}\right) k^{*} \\
& =\left(1-\frac{\beta}{1+r} \frac{q_{1}}{q_{0}}\right)\left(\frac{p R+q_{1}-(1+r) q_{0}}{c}-\frac{(1-p)(1-\beta)(1+r) q_{0}}{\beta c}\right) .
\end{aligned}
$$

If $w \geq w^{\min }$, the entrepreneur is not credit-constrained. He can borrow $b=q_{0}\left(k^{*}-w\right)$ and achieve his preferred scale of production. However, if $w<w^{\min }$, the entrepreneur is creditconstrained with the scale of production equal to:

$$
k=\frac{q_{0} w}{q_{0}-\beta q_{1} /(1+r)} .
$$

The effect of liquidation costs on the minimum endowment requirement is ambiguous. On the one hand, costly liquidation lowers the desired production scale for the unconstrained entrepreneur. This lowers the minimum endowment requirement. On the other hand, costly liquidation reduces the maximum possible degree of leverage for the constrained entrepreneur. It may thus be possible that an increase in the liquidation cost makes external finance so expensive that the entrepreneur is no longer credit-constrained. In this case, the entrepreneur simply chooses to borrow less.

\section{Susceptibility to Interest Rate Shocks}

Let us now examine the response of production to an increase in the riskless rate. The prediction implied by this framework is that small changes in $r$ have large consequences when liquidation costs are large. To see this, note that

$$
\begin{aligned}
\frac{\partial k^{*}(r ; \beta)}{\partial r} & =\frac{\partial}{\partial r}\left(\frac{p R+q_{1}-(1+r) q_{0}}{c}-\frac{(1-p)(1-\beta)(1+r) q_{0}}{\beta c}\right) \\
& =-\left(1+\frac{(1-p)(1-\beta)}{\beta}\right) \frac{q_{0}}{c}
\end{aligned}
$$

is decreasing in the liquidation cost.

The intuition that drives this result is as follows. As the cost of funds increases, the bank needs to raise more revenue. However, the possibilities of raising revenue are restricted. Due to the non-verifiability of returns, the bank is forced to equalize revenue across realizations of the productivity shock. The IC constraint dictates equality between loan rate repayment and collateral liquidation proceeds. Therefore, in order to boost revenue without 
compromising incentives, collateralization must increase. And, the more costly collateral liquidation is, the more strongly collateralization needs to be increased. This motivates the entrepreneur to further reduce the scale of production.

Due to costly liquidation, interest rate changes have powerful effects on the feasibility of the optimal contract. Especially when liquidation costs are high, a small increase in the interest rate may lead to a violation of the entrepreneur's IR constraint as leveraging simply becomes too costly. Collateral is beneficial as an incentive device but at the same time makes the feasibility of the contract more susceptible to changes in interest rates.

\section{Aggregate UnCertainty}

The previous section examined the optimal contractual arrangement between banks and entrepreneur-borrowers. It was shown how non-verifiability and costly asset liquidation necessarily lead to the bank breaking even whatever the realization of the productivity shock. Due to the non-verifiability assumption, the proceeds from collateralization must be at least as much as those from loan rate repayment. Due to the costly asset liquidation assumption, this weak inequality turns into an equality. Therefore, regardless of idiosynchratic uncertainty about productivity, banks always break even in this economy.

This section revisits the optimal contract in an environment with aggregate uncertainty about the value of collateral. Depending on the contractual form, banks now no longer break even in every possible state of the world. Aggregate uncertainty about the value of collateral is introduced as follows. We assume that, for exogenous reasons, the date-1 asset price equals $q_{H}$ in the good state of nature and $q_{L}$ in the bad state (with $q_{H}>q_{L}$ ). The good state occurs with probability $\pi$ and the bad state with probability $1-\pi$. Let $q_{1} \equiv \pi q_{H}+(1-\pi) q_{L}$, which is the expected asset price as of date 0 .

\section{A. Contracting Under Aggregate Uncertainty}

We are looking for a contract between bank and entrepreneur that specifies (i) the degree of leverage (implied by a choice of $k$ ), (ii) the net loan rate in the good and the bad state $\left(\alpha_{H}\right.$ and $\alpha_{\ell}$ ) and (iii) the degree of asset collateralization in the good and the bad state $\left(\gamma_{H}\right.$ and $\left.\gamma_{L}\right)$.

The problem to solve is given by: 


$$
\begin{aligned}
& \max _{k, \alpha_{H}, \alpha_{L}, \gamma_{H}, \gamma_{L}} \pi\left[p\left(R+q_{H}\right) k-p\left(1+\alpha_{H}\right) q_{0}(k-w)+(1-p)\left(1-\gamma_{H}\right) q_{H} k\right] \\
& +(1-\pi)\left[p\left(R+q_{l}\right) k-p\left(1+\alpha_{L}\right) q_{0}(k-w)+(1-p)\left(1-\gamma_{L}\right) q_{L} k\right] \\
& -(1+r) q_{0} w-\frac{c}{2} k^{2}
\end{aligned}
$$

subject to the incentive constraints for the good and the bad state $\left(\mathrm{IC}_{\mathrm{H}}\right.$ and $\left.\mathrm{IC}_{\mathrm{L}}\right)$ :

$$
\begin{aligned}
& \left(1+\alpha_{H}\right) q_{0}(k-w) \leq \beta \gamma_{H} q_{H} k, \\
& \left(1+\alpha_{L}\right) q_{0}(k-w) \leq \beta \gamma_{L} q_{L} k,
\end{aligned}
$$

the IR constraint of the bank:

$$
\begin{aligned}
& \pi\left[p\left(1+\alpha_{H}\right) q_{0}(k-w)+(1-p) \beta \gamma_{H} q_{H} k\right] \\
& +(1-\pi)\left[p\left(1+\alpha_{L}\right) q_{0}(k-w)+(1-p) \beta \gamma_{L} q_{L} k\right] \\
& \geq(1+r) q_{0}(k-w)
\end{aligned}
$$

and the IR constraint of the entrepreneur:

$$
\begin{aligned}
& \pi\left[p\left(R+q_{H}\right) k-p\left(1+\alpha_{H}\right) q_{0}(k-w)+(1-p)\left(1-\gamma_{H}\right) q_{H} k\right] \\
& +(1-\pi)\left[p\left(R+q_{L}\right) k-p\left(1+\alpha_{L}\right) q_{0}(k-w)+(1-p)\left(1-\gamma_{L}\right) q_{L} k\right] \\
& -(1+r) q_{0} w-\frac{c}{2} k^{2} \\
& \geq\left(p R+q_{1}\right) w-(1+r) q_{0} w-\frac{c}{2} w^{2} \geq 0 .
\end{aligned}
$$

Note that there are now two incentive constraints, to ensure that strategic default is prevented in both states of nature. Since collateral liquidation is costly, we know that the optimal contract will economize as much as possible on the use of collateral. $\mathrm{IC}_{\mathrm{H}}$ and $\mathrm{IC}_{\mathrm{I}}$ will therefore both be binding. Due to competition the bank's IR constraint will also be binding. Substituting the IC constraints into the bank's IR constraint yields:

$$
\pi\left(\beta \gamma_{H} q_{H} k\right)+(1-\pi)\left(\beta \gamma_{L} q_{L} k\right)=(1+r) q_{0}(k-w)
$$

We explore two types of contract that may emerge from this problem: a contingent contract and an uncontingent contract. In both cases we restrict attention to renegotiationproof contracts. We show that both types of contract lead to the same welfare level. For the 
moment, we also restrict attention to the case where the collateral constraint does not bind $(\gamma<1)$. Binding collateral constraints will be discussed in the next section.

\section{B. Contingent Contract}

State-contingency in this context refers to dependence of the entrepreneur's liabilities on the state of nature. This means that the loan rate and/or the value of the collateralized asset base depend on the realization of the asset price. In other words, $\alpha_{H}$ and $\alpha_{L}$ may differ from each other and so may $\gamma_{H} q_{H}$ and $\gamma_{L} q_{L}$.

Without loss of generality, we focus on the case where $\gamma_{H}=\gamma_{L} \equiv \gamma .^{\prime}$ From (5) it then follows that

$$
\gamma=\frac{1+r}{\beta} \frac{q_{0}}{q_{1}} \frac{(k-w)}{k}
$$

where $q_{1} \equiv \pi q_{H}+(1-\pi) q_{L}$.

Using this latter expression as well as the binding IC constraints, the problem can be written in the following convenient way:

$$
\max _{k}\left(p R+q_{1}\right) k-(1+r) q_{0} k-\frac{(1-p)(1-\beta)(1+r)}{\beta} q_{0}(k-w)-\frac{c}{2} k^{2}
$$

subject to the entrepreneur's IR constraint. Note that this expression coincides with what we derived in the absence of aggregate uncertainty. The only difference is that $q_{1}$ now refers the expected date 1 asset price. If the entrepreneur's IR constraint is not violated, the optimal contingent contract (among the contracts that we focus on) is characterized by:

\footnotetext{
${ }^{1}$ Alternative state-contingent contracts where the degree of collateralization does depend on the asset price result in exactly the same level of welfare.
} 


$$
\begin{aligned}
k & =\frac{p R+q_{1}-(1+r) q_{0}}{c}-\frac{(1-p)(1-\beta)(1+r) q_{0}}{\beta c} \\
\alpha_{H} & =(1+r) \frac{q_{H}}{q_{1}}-1 \\
\alpha_{L} & =(1+r) \frac{q_{L}}{q_{1}}-1 \\
\gamma_{H} & =\gamma_{L}=\frac{(1+r)}{\beta} \frac{q_{0}}{q_{1}} \frac{(k-w)}{k} .
\end{aligned}
$$

The level of welfare is the same as if there were no aggregate uncertainty:

$$
\begin{aligned}
W & =\frac{1}{2 c}\left(p R+q_{1}-(1+r) q_{0}-\frac{(1-p)(1-\beta)(1+r) q_{0}}{\beta}\right)^{2} \\
& +\frac{(1-p)(1-\beta)(1+r)}{\beta} q_{0} w .
\end{aligned}
$$

Note that the contingent contract results in bank profit variability. The bank now makes a profit in the good state and a loss in the bad state.

\section{Uncontingent Contract}

The state-uncontingent contract insulates the liabilities of the entrepreneur from asset price volatility. This is achieved by setting $\alpha_{H}=\alpha_{L}=\alpha$ and $\gamma_{H} q_{H}=\gamma_{L} q_{L}$. From (5) we can derive $\gamma_{H}$ and $\gamma_{L}$. Note that $\gamma_{H}<\gamma_{L}$ since $q_{H}>q_{L}$. Again, it turns out that the objective function can be conveniently rewritten as (6). Provided that the entrepreneur's IR constraint is not violated, the optimal uncontingent contract is characterized by:

$$
\begin{aligned}
k & =\frac{p R+q_{1}-(1+r) q_{0}}{c}-\frac{(1-p)(1-\beta)(1+r) q_{0}}{\beta c} \\
\alpha_{H} & =\alpha_{L}=r \\
\gamma_{H} & =\frac{(1+r)}{\beta} \frac{q_{0}}{q_{H}} \frac{(k-w)}{k} \\
\gamma_{L} & =\frac{(1+r)}{\beta} \frac{q_{0}}{q_{L}} \frac{(k-w)}{k} .
\end{aligned}
$$

The level of welfare is again the same as in the case without aggregate uncertainty. Note that the uncontingent contract does not cause bank profit variability. Collateral 
requirements vary countercyclically with asset prices so that stable revenue is maintained across states of nature.

\section{Credit Constraints, Bank Solvency and the Public Supply of Liquidity}

The previous section identified costly asset liquidation as a first complication for the provision of finance. We now study a second complication: contracts with collateral requirements introduce relative price risk. Aggregate uncertainty about collateral values may under certain conditions be a source of credit constraints. We will establish that aggregate uncertainty may be particularly troublesome when both banks and borrowers are poorly capitalized. We will also identify a role for the public supply of liquidity.

\section{A. Credit Constraints Under Aggregate Uncertainty}

We examine the consequences of aggregate uncertainty for agents that are creditconstrained. Consider first the uncontingent contract. Since the credit-constrained entrepreneur will want to be leveraged to the maximum possible extent, the degree of collateralization will hit its upper bound. In the presence of aggregate uncertainty, this upper bound will bind in the bad state of nature. This is because the uncontingent contract requires a higher degree of collateralization when the asset price is low. As a result, we have:

$$
\gamma_{H}=\frac{(1+r)}{\beta} \frac{q_{0}}{q_{H}} \frac{(k-w)}{k}
$$

and

$$
\gamma_{L}=\frac{(1+r)}{\beta} \frac{q_{0}}{q_{L}} \frac{(k-w)}{k}=1
$$

The latter condition will pin down the feasible scale of production:

$$
k=\frac{q_{0} w}{q_{0}-\beta q_{i} /(1+r)},
$$

which is lower than in the case without aggregate uncertainty since $q_{L}<q_{1}$.

In contrast, the contingent contract does not require the degree of collateralization to vary countercyclically. The contingent contract we studied before simply sets $\gamma_{H}=\gamma_{L} \equiv \gamma$. Maximum collateralization then implies: 


$$
\gamma_{H}=\gamma_{L}=1
$$

leaving the feasible scale of production unaffected at:

$$
k=\frac{q_{0} w}{q_{0}-\beta q_{1} /(1+r)}
$$

In sum, the equivalence of welfare between the contingent and uncontingent contract breaks down when the entrepreneur is credit-constrained. Since the degree of leverage is not affected by asset price volatility, the contingent contract now dominates the uncontingent contract.

\section{B. Bank Solvency Under Aggregate Uncertainty}

We are now ready to examine the consequences of bank solvency constraints for the provision of external finance to credit-constrained entrepreneurs. We show that bank solvency considerations affect the nature of contracting by limiting the degree of asset price contingency and thereby creating an independent source for credit constraints.

Let $\phi$ denote the capital-to-assets ratio of the representative bank in this economy. Solvency requires that the losses in the bad the state of nature do not exceed the bank's net worth:

$$
\phi(1+r) q_{0}(k-w) \geq(1+r) q_{0}(k-w)-\beta q_{L} \gamma_{L} k
$$

or

$$
\beta q_{L} \gamma_{L} k \geq(1-\phi)(1+r) q_{0}(k-w)
$$

Bank solvency considerations will come into play when asset price volatility is high relative to the bank's net worth. The precise condition under which bank solvency will matter is given by:

$$
q_{L}<\left(\frac{(1-\phi) \pi}{\phi+(1-\phi) \pi}\right) q_{H}
$$

If this condition holds, then financing a credit-constrained entrepreneur up to scale $\widetilde{k}=q_{0} w /\left(q_{0}-\beta q_{1} /(1+r)\right)$ will push the bank into insolvency in the bad state of nature. To 
see this, note that $\beta q_{L} \gamma_{L} \tilde{k}<(1-\phi)(1+r) q_{0}(\tilde{k}-w)=(1-\phi) \beta q_{1} \gamma_{L} \tilde{k}$ for $\gamma_{L}=1$ and $q_{L}<(1-\phi) q_{1}$.

If condition ( 7 ) holds, the solvency constraint binds and can be rewritten as:

$$
1=\gamma_{L}=(1-\phi) \frac{(1+r)}{\beta} \frac{q_{0}}{q_{L}} \frac{(k-w)}{k}
$$

Substituting the latter expression into the bank's binding IR constraint,

$$
\pi\left(\beta \gamma_{H} q_{H}\right)+(1-\pi)\left(\beta \gamma_{L} q_{L}\right)=(1+r) q_{0} \frac{(k-w)}{k}
$$

yields the optimal degree of collateralization in the good state of nature:

$$
\gamma_{H}=\frac{q_{L}}{q_{H}}\left(\frac{\phi}{(1-\phi) \pi}+1\right) .
$$

From (8) we can derive the optimal project size:

$$
k=\frac{q_{0} w}{q_{0}-\beta q_{L} /[(1-\phi)(1+r)]}
$$

Another way to determine whether the solvency condition binds is in terms of the capital-toassets ratio. Let

$$
\phi^{*} \equiv \frac{\pi\left(q_{H}-q_{L}\right)}{q_{L}+\pi\left(q_{H}-q_{L}\right)},
$$

with $0<\phi^{*}<1$. We can then summarize our results as follows. If $\phi=0$, the bank has no capital cushion and cannot afford to suffer any losses resulting from asset price depreciation. The optimal contract will therefore correspond to the uncontingent contract and the project size will equal:

$$
k=\frac{q_{0} w}{q_{0}-\beta q_{L} /(1+r)} .
$$


If $0<\phi<\phi^{*}$, the bank can withstand a certain degree of asset price volatility but still has to reduce its exposure in order to survive in the bad state of nature. The optimal contract will correspond to a contingent contract with $\gamma_{H}<\gamma_{L}=1$. The scale of operation is given by:

$$
k=\frac{q_{0} w}{q_{0}-\beta q_{L} /[(1-\phi)(1+r)]} .
$$

If $\phi \geq \phi^{*}$, the bank is immune with regard to the degree of asset price volatility in this economy. The optimal contract will correspond to a contingent contract with $\gamma_{H}=\gamma_{L}=1$. The project size equals:

$$
k=\frac{q_{0} w}{q_{0}-\beta q_{1} /(1+r)} .
$$

These results can also be more generally related to agents that are not initially creditconstrained. If the uncontingent contract remains feasible given a particular degree of asset price volatility, then bank solvency constraints are irrelevant. If the uncontingent contract is not feasible for that degree of asset price volatility, then credit constrants may occur depending on the extent of bank capitalization.

\section{The Public Supply of Liquidity}

The combination of poor bank and borrower capitalization may lead to credit tightening in the face of aggregate uncertainty. We have shown that non-verifiability may produce credit constraints which in turn lead to a trade-off between high leverage and low bank profit variability. A credit-constrained entrepreneur in this economy will want to sign a contingent contract to ensure maximum leverage. At the same time, the contingent contract produces asset volatility that may be too high from the perspective of the bank. In response, poorly capitalized banks will reduce their exposure and this leads to a further welfare loss.

Since the uncertainty in this model is taken to be aggregate, there is no scope for private insurance. As a result, a role for public insurance emerges in the form of government supplied liquidity. This is particularly so if the environment is prone to a great deal of asset price volatility and if it is difficult to improve on the capitalization of banks. In the context of this model, the government could tax banks in the good states of nature and provide them with liquidity in the bad states. The extent to which the government needs to provide liquidity can be measured by $\phi^{*}-\phi$, where $\phi$ is the bank's capital-to-assets ratio and $\phi^{*}$ is the threshold value beyond which the solvency constraint does not bind.

This is somewhat reminiscent of the government acting as a co-signer (as in Besanko and Thakor, 1987). Such an arrangement serves to increase the availability of collateral and 
this is exactly what credit-constrained entrepreneurs need. The state-contingent provision of liquidity could also be interpreted as countercyclical monetary policy, where monetary policy is lenient when asset prices are low (and liquidity needs are the highest) and monetary policy is tight when asset prices are high.

The beneficial role of government supplied liquidity (or, alternatively, countercyclical monetary policy) must be balanced with potential dangers that the model does not address. For example, as has been pointed out by Krugman (1998), Corsetti, Pesenti and Roubini (1998) and others, implicit government guarantees may create moral hazard problems that lead to excessive indebtedness and overinvestment. In addition, asset price collapse may cause a problem of regulatory forebearance. Governments may be tempted to compromise on regulation standards and to delay financial restructuring reforms. Finally, financial fragility may also undermine long-term price stability by triggering monetary policy forebearance, that is to adopt, in the face of asset price collapse, a looser policy stance than is justified by macroeconomic conditions. ${ }^{2}$

\section{CONCluding Remarks}

This paper has highlighted two complications associated with collateral requirements in the provision of external finance. We have argued that costly asset liquidation may sharply reduce the extent to which wealth-constrained entrepreneurs are leveraged. We have shown that aggregate asset price uncertainty may leave borrowers deprived from credit when banks are poorly capitalized. Finally, we have also suggested that the state-contingent provision of liquidity by the government, also interpreted as countercyclical monetary policy, may be useful in the environment that was studied here.

We conclude with a brief discussion of two possible avenues for future research. We found that the degree of leverage is highly susceptible to interest rate changes when the liquidation cost is high. A first possible application of this result relates to the desirability of interest rate smoothing. Interest rate smoothing can be rationalized if there are convex adjustment costs in the scale of production. Since adjustment costs increase with the size of the response of production, interest rate smoothing may be more desirable when the cost of asset liquidation is high.

A second application concerns the micro-foundations of second-generation currency crisis models. These models are based on the notion that defending a fixed exchange rate is a matter of trade-offs. The self-fulfilling nature of a crisis hinges on the requirement that the costs of defending a peg outweigh the benefits in the event of a speculative attack (see, for

\footnotetext{
${ }^{2}$ See IMF (2000, p. 128).
} 
example, Obstfeld, 1986 and 1994). The implication of our model is that countries with high liquidation costs may be more prone to speculative pressure. This is because the cost of withstanding an attack in terms of reduced financial intermediation is much higher when the liquidation cost is high. Speculators who understand the increased reluctance of policy makers to raise rates therefore attack sooner rather than later. 


\section{References}

Bernanke, Ben, and Mark Gertler, 1989, "Agency Costs, Net Worth, and Business Fluctuations," American Economic Review, 79 (1), pp. 14-31 (March).

Besanko, David, and Anjan Thakor, 1987, "Collateral and Rationing: Sorting Equilibria in Monopolistic and Competitive Credit Markets," International Economic Review, 28 (3), pp. 671-89 (October).

Bester, Helmut, 1985, "Screening vs. Rationing in Credit Markets with Imperfect Information," American Economic Review, 75 (4), pp. 850-5 (September).

Boot, Arnoud, Thakor, Anjan, and Gregory Udell, 1991, "Secured Lending and Default Risk: Equilibrium Analysis, Policy Implications and Empirical Results," Economic Journal, 101, pp. 458-72 (May).

Caballero, Ricardo, and Arvind Krishnamurthy, 2000,"Emerging Markets Crises: An Asset Markets Perspective," mimeo, MIT, (February).

Corsetti, Giancarlo, Paolo Pesenti, and Nouriel Roubini, 1998, "Paper Tigers? A Preliminary Assessment of the Asian Crisis," mimeo, Yale University (June).

Hart, Oliver, and John Moore, 1994,"A Theory of Debt Based on the Inalienability of Human Capital," Quarterly Journal of Economics, 109 (4), pp. 841-79.

Holmstrom, Bengt, and Jean Tirole, 1997, "Financial Intermediation, Loanable Funds, and the Real Sector," Quarterly Journal of Economics, 112 (3), pp. 663-91.

, "Private and Public Supply of Liquidity, 1998," Journal of Political Economy, $106(1)$, pp. 1-40.

International Monetary Fund, 2000, World Economic Outlook, Washington, D.C. (April).

Kiyotaki, Nobuhiro, and John Moore, 1997,"Credit Cycles," Journal of Political Economy, 105 (2), pp. 211-48 (April). , 1999, "Indexation and Insurance: A Stochastic Model of Credit Cycles," mimeo, LSE.

Krishnamurthy, Arvind, 1999, "Collateral Constraints and the Amplification Mechanism," mimeo, Northwestern University (October).

Krugman, Paul, 1998, "What Happened to Asia?" mimeo, MIT, (January). 
Obstfeld, Maurice, 1986, "Rational and Self-Fulfilling Balance-of-Payments Crises," American Economic Review, 76 (1), pp. $72-81$ (March). , 1994, "The Logic of Currency Crises," Cahiers Economiques et Monetaires (Banque de France), 43, pp. 189-213.

Shleifer, Andrei, and Robert Vishny, 1992, "Liquidation Values and Debt Capacity: A Market Equilibrium Approach," Journal of Finance, 47 (4), pp. 1343-66 (September). 